\title{
The study of the processes of influence of auxiliary agents on grape processing products
}

\author{
Larisa Chemisova*, Olga Sheludko, Ekaterina Mitrofanova, Anastasia Shirshova, and \\ Vitaly Redka
}

Federal State Budget Scientific Institution «North Caucasian Federal Scientific Center of Horticulture, Viticulture, Wine-making», 39 str. 40 Let Pobedy, Krasnodar, 350901, Russia

\begin{abstract}
The study of the processes of the influence of capping and packaging on the quality of finished products during storage is an important component of maintaining the stable quality of wines. It has been found that packaging has a significant impact on the evolution of wine during storage. It was found that the variation in the content of total sulfur dioxide and dissolved oxygen depending on the type of packing has an inverse relationship. The dissolved oxygen content was higher in wines bottled in glass bottles and PET (polyethylene terephthalate) bottles compared to products in composite packaging. These results are metrics to consider when choosing the packaging depending on the intended distribution and marketing method. The closures are the source of a variety of microbiological and chemical substances in wine. The nomenclature depends on the kind and the type of used plugs. Natural cork, in most cases, enriches the wine with substances of microbiological origin, as well as their waste products. Synthetic closures introduce chemical components that are not inherent in the nature of wine, thereby disrupting the aroma and color of the product.
\end{abstract}

\section{Introduction}

Grapes are the raw material for a wide range of products. Its popularity is primarily due to the content in it of a huge amount of useful substances, which include vitamins, macro- and microelements, proteins and amino acids, including essential ones, fats and fatty acids, sterols, and carbohydrates. In addition, many red grapes are highly antioxidant. Considering the focus of technical grape varieties, this is, of course, the production of various types of wine products.

Nowadays, the strict requirements are imposed on the quality of such products, and compliance with them is regularly monitored.

It is well known [1-4] that in the process of storing wines, their aging takes place, at which pleasant taste notes appear, arising from the properties of grapes, fermenting yeast, possible aromatic compounds that are transferred from the barrels during further aging and storage and ripening time in the package. However, some physical and chemical factors can shorten the shelf life of wine up to several months or even weeks, when such visual defects quickly

\footnotetext{
* Corresponding author: nognichenko@mail.ru
} 
arise because of acidic phenomena, as a rule, due to excessive wine. The variability of this deterioration of aromatic properties is strongly influenced by differences in the permeability for oxygen between different types of packaging and closures [6, 7]. Accordingly, the study of the influence of auxiliary means, namely, consumer packaging and its closure on the change in the quality of wines is relevant.

\section{Materials and methods}

To study the influence of packaging materials and closures on the composition of wine products, the objects of research were table red and white dry and semi-sweet wines, bottled in various types of packaging (PET bottles, complex packaging "bag in a box", packaging materials), as well as combined in a glass bottle. In addition, natural cork and polymer corks were the objects of research.

Investigations of the quality of prototypes of wines, packaging and closures were carried out by conventional physicochemical methods, including using microscopy, as well as by means of gas chromatography and mass spectrometry.

Organoleptic analysis of the quality of the investigated products was carried out by the tasting committee of the FSBSI NCFSCHVW.

\section{Results and discussion}

Organoleptic analysis of more than 20 samples of wines in various consumer packages made it possible to study the change in the quality of wines in relation to the configuration of the package. As a result, it was found that the wines bottled in polyethylene terephthalate had extraneous tones and flavors in aroma and taste, characterized as synthetic. Products in complex packaging "bag in a box" with a shelf life of 3 years or more had a negative characteristic and were completely "destroyed".

After filling and sealing, the consumer packaging contains oxygen from the initial bulk product, oxygen in free space remaining after any gas flushing or vacuum application during the application of the closure, and any oxygen inside the closure structure, especially with the cellular structure, if such was used (Fig 1). This last oxygen will move over the time, part of the oxygen will escape from the bottle into the surrounding environment, and some will get inside. Over the time, steady penetration can be established.

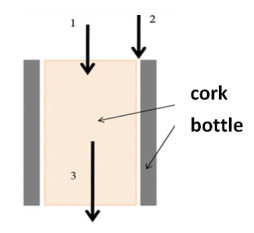

Fig. 1 - Ways of oxygen entering the bottle during storage and aging of wine, where:

1 - penetration through the pores of the cork;

2 - diffusion at the interface between the closure and the bottle;

3 - oxygen removed from the closure during the compression closure

Since the rate of penetration of oxygen $\left(\mathrm{O}_{2}\right)$, sulfur dioxide $\left(\mathrm{SO}_{2}\right)$ and carbon dioxide $\left(\mathrm{CO}_{2}\right)$ through packaging, including the cork, affects the shelf life of both packaged food and bottled beverages, i.e. promotes or limits oxidation. Accordingly, the permeability of materials to gases plays a fundamental role as a means of assessing and predicting changes in the quality of packaged products [8-11].

As a result of research, it has been established that the amount of dissolved oxygen in wine poured into a package varies depending on the type of package itself. The highest $\mathrm{O}_{2}$ 
content was observed in wines in glass bottles (up to $8.96 \mathrm{mg} / \mathrm{dm}^{3}$ ), and the lowest - in a package-in-a-box package $\left(6.77 \mathrm{mg} / \mathrm{dm}^{3}\right)$. It was also revealed that the content of dissolved oxygen in wines in a package-in-a-box package and a bottle made of polyethylene terephthalate was practically the same.

The concentration of $\mathrm{SO}_{2}$ in the studied wines was the lowest in the variant with packaging made of combined materials, especially with a long shelf life $\left(36.0 \mathrm{mg} / \mathrm{dm}^{3}\right)$. A similar picture was observed with wines bottled in a complex package "bag in a box" with a long aging $\left(37.0 \mathrm{mg} / \mathrm{dm}^{3}\right)$. The level of sulfur dioxide in wines placed in glass bottles was at the level of $68.0-94.0 \mathrm{mg} / \mathrm{dm}^{3}$. Presumably, the variation of sulfur dioxide depends to the greatest extent on the aging time, and not on the configuration of the packaging in which the wine is poured.

When considering the content of $\mathrm{SO}_{2}$ and $\mathrm{O}_{2}$ together, their inverse correlation should be noted, with the exception of samples with long-term storage. Obviously, this happens as a result of reciprocal processes (oxidation and reduction) occurring in wines, that is, oxygen, which is responsible for oxidative processes, is "compensated" due to the reducing properties of $\mathrm{SO}_{2}$.

In addition, the evolution of the aromatic profile of wine, packed in glass and polyethylene terephthalate bottles, was studied. Wine, stored in both types of bottles, was clearly differentiated after 5 years, but only in a limited number of compounds. A more pronounced decrease in the content of oxygen-sensitive compounds, such as methanol, was observed in bottles made of polyethylene terephthalate, as well as the appearance of oxidizing and aging aromatic compounds such as ethyl pyruvate, furfural or dioxans in higher concentrations.

As a result of the tests carried out on samples of natural cork, presented by the wineries, already at the stage of their preparation, defects in appearance were noticeable. The corks had deep cracks over the entire surface, a large number of wormholes, and the presence of a dry vein was also noted. Moreover, these defects had insignificant differences depending on the type of the examined probes.

In Figure 2 (a) and (b), it is clearly demonstrated that after a 3-week contact on the top of the contiguity of the tube with wine, the destruction of the glue and the swelling of the granules (opening of the top). Figure 2 (c) allows to estimate the degree of capillary, which already at this stage of contact was more than $2 \mathrm{~mm}$.

The microbiological picture of the sediment isolated from this bottle testified to the presence of an adhesive substance that passed into the wine from the cork seal (Fig. 2, d).

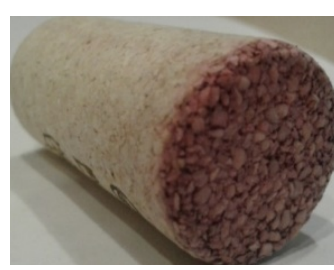

$a$

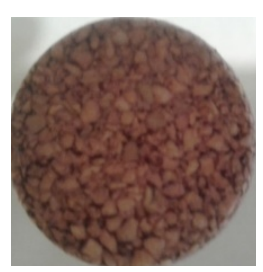

$b$

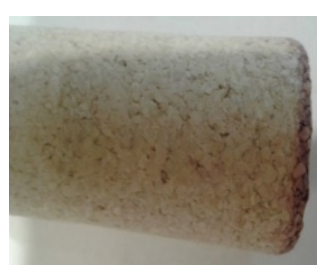

$c$

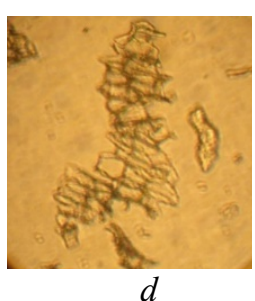

Fig. 2. Fine agglomerated cork removed from the bottle 3 weeks after capping

Figure 3 shows photographs of a substandard natural cortex with pronounced defects in appearance before capping (a) and after removal from the bottle (b) with a pronounced capillary zone (penetration of wine), due to which the contact layer is destroyed and the cork and glue particles are "washed out" in the wine. 


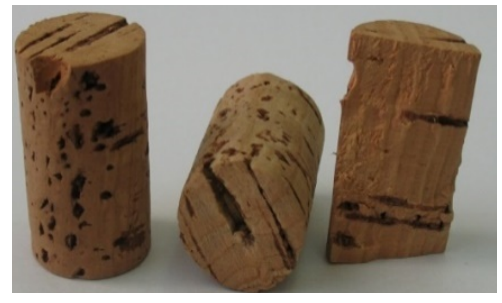

$a$

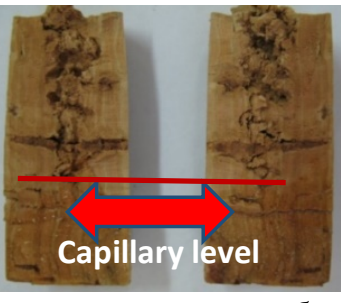

6

Fig. 3. Sectional view of a natural cork

Exceeding the standards for the content of sample dust leads to its ingress into the finished product during storage and contributes to the formation of precipitates not typical for the nature of wines (Fig. $4 \mathrm{a}, \mathrm{b}$ ).

Non-compliance with the established level of humidity and the apparent density of agglomerated and collection corks leads to its crumbling and destruction of the cork, as well as to a decrease or even loss of production sealing properties, and removing such a cork from the bottle may be unsafe due to its "rupture" and the possibility of damage to the neck of the glass bottle (Fig. 4 c, d).

As a result of the study of volatile substances of the extracts of cork plugs, compounds are found that are not characteristic of cork plugs, as ethyl citrate, 2,3-dimethylmaleic anhydride, 2,5-furandicarboldehyde, 4-methylacetophenone, 2- (2-butoxyethoxy) ethyl acetate, 2-butoxyethoxy) ethyl acetate, 2- acetophenone, 1H-pyrrol-2-carboxyaldehyde, etc.

In addition, was identified ochracin, which is a derivative of coumarin and has teratogenic activity and anticoagulant ability. Presumably, this substance can be a precursor of trichloroanisol and, in the future, its accumulation will occur in the cork, and upon contact of the cork with the product, it will transform into a drink.

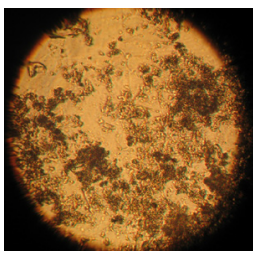

$a$

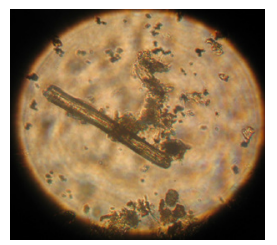

$b$

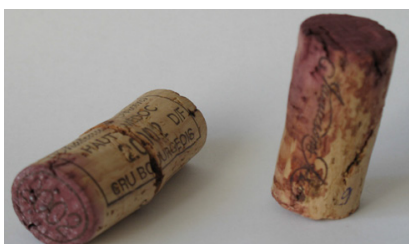

C

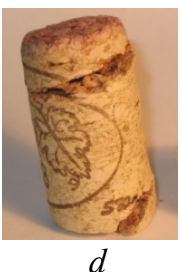

$d$

Fig. 4. Results of non-compliance of plugs with established requirements:

a, b) microscopic images of wine sediments containing particles of dust, glue and the main substance of the cork, single cells of microorganisms,

$c, d)$ result of inconsistency of corks with indicators of humidity and apparent density

Another important negative component of steel is the detection of "transformed" or they are also called "wandering" tones of cortex. They are characterized by dusty, earthy, damp and even musty tones. These can include such substances as: guoyacol, pyrocatechin, geosmin, etc. [12-14].

The effect of polymer closures on the volatile composition of wine was assessed using solid-phase microextraction in free space over white wine in combination with gas chromatography-mass spectrometry. The main differences in the profile of volatile components of wine were observed between cork and synthetic closures, including statistically significant changes for 2,4-di-tert-butylphenol and trans-4-tertbutylcyclohexanol, which were first identified in wines that were corked with synthetic corks and micro-agglomerated cork, respectively [15], since a large amount of glue is used in its manufacture. In addition, sensory analysis of wine sealed with a cork stopper revealed the 
highest scores for intensity and quality of aroma, as well as its balance. On the other hand, wine sealed with synthetic closures was characterized by oxidizing properties, the lowest $\mathrm{SO}_{2}$ level and the highest color intensity.

\section{Conclusion}

It was revealed that the usual oenological indicators such as gas content $\left(\mathrm{O}_{2}, \mathrm{SO}_{2}\right)$ varied significantly with respect to the packaging, there were observed specific oxidizing compounds that negatively affect the organoleptic characteristics depending on the various configurations of the packaging.

An inverse dependence of the variation of physicochemical parameters (the content of total sulfur dioxide and dissolved oxygen) has been established. The highest concentration of $\mathrm{O}_{2}$ was noted in the products placed in glass bottles and bottles made of polyethylene terephthalate, and the lowest in wines in packages made of combined materials, which proves the occurrence of permeation and absorption processes.

Natural cork, in most cases, enriches the wine with substances of microbiological origin, as well as the products of their vital activity, which, in the course of oxidative and biotechnological processes occurring in the drink during storage, transform into various, including external quality and safety of wine. Synthetic closures introduce chemical components that are not inherent in the nature of wine, thereby disrupting the aroma and color of the product.

Acknowledgments. The research was carried out with the financial support of the Kuban Science Foundation, project number MFI-20.1-2 / 20

\section{References}

1. M. Sáenz-Navajasab, J. Avizcuric, J. Ballesterad, P. Fernández-Zurbanoc, V. Ferreirab, D. Peyronac, D.Valentinae, LWT, 60(1), 400-411 (2015) https://doi.org/10.1016/j.lwt.2014.09.026

2. D. Liu, R.R. Xing, Z. Li, Q.H. Pan, Eur. Food. Res. Technol., 242, 1937-1948 (2016) https://doi.org/10.1007/s00217-016-2693-1

3. C.M. Oliveira, A.C.S. Ferreira, V. De Freitas, A.M.S. Silva, Food Res. Int., 44 (5), $1115-$ 1126 (2011) https://doi.org/10.1016/j.foodres.2011.03.050

4. M.A. Silva, M. Julien, M. Jourdes, P.L. Teissedre, Eur. Food. Res. Technol., 233, 905-914 (2011). https://doi.org/10.1007/s00217-011-1603-9

5. C.M. Mayr, D.L. Capone, K.H. Pardon, C.A. Black, D. Pomeroy, I.L. Francis, J Agric. Food Chem., 63 (13), 3394-3401 (2015) https://doi.org/10.1021/jf505803u

6. P. Godden, D. Cozzolino, P. Smith, B. Dambergs, W. Cynkar, N. Shah, E. Robinson, I. Pretorius (2018) https://www.researchgate.net/publication/323108793

7. M.Z. Bekker, M.E. Smith, P.A. Smith, E.N. Wilkes, Molecules, 21(9), 1214 (2016) https://doi.org/10.3390/molecules21091214

8. J. Chanutab, A. Lagorceab, S. Lequinab, R. Gougeonac, J. Simonb, J. Bellatb, T. Karbowiaka, Polymer Test., 93, $106924 \quad$ (2021) https://doi.org/10.1016/j.polymertesting.2020.106924

9. A. Baiano, A. De Gianni, Eur. Food Res. Technol., 242, 1857-1867 (2016) https://doi.org/10.1007/s00217-016-2685-1

10. J. Echave, M. Barral, M. Fraga-Corral, M. Prieto, J. Simal-Gandara. Molecules, 26(3), 713 (2021) https://doi.org/10.3390/molecules26030713 
11. C. Coelho1, P. Julien, M. Nikolantonaki, L. Noret, M. Magne, J. Ballester, R.Gougeon, Front. Chem., 6, 95 (2018) https://doi.org/10.3389/fchem.2018.00095

12. M. Ugliano, J. Agric. Food Chem., 61(26), 6125-6136 (2013) https://pubs.acs.org/doi/10.1021/jf400810v

13. K. Crouvisier-Urion, J.-P. Bellat, R.D. Gougeon, T. Karbowiak, Trends in Food Sci. Technol., 78, 255-269 (2018) https://doi.org/10.1016/j.tifs.2018.05.021

14. J. Azevedo, I. Fernandes, P. Lopes, I. Roseira, M. Cabral, N. Mateus, V. Freitas, Eur. Food Res. Technol., 239, 951-960 (2014). https://doi.org/10.1007/s00217-014-2292-y

15. A.S. Oliveira, I. Furtado, M. de Lourdes Bastos, P. Guedes de Pinho, J. Pint, Food Packag. Shelf Life, 23, 100465 (2020) https://doi.org/10.1016/j.fpsl.2020.100465 